\title{
Verteporfin inhibits cell proliferation and induces apoptosis in different subtypes of breast cancer cell lines without light activation
}

\author{
Changran Wei ${ }^{1}$ and Xiangqi Li ${ }^{1,2^{*}}$
}

\begin{abstract}
Background: Breast cancer (BC) can be divided into five subtypes: Lumina1A, Lumina1B, HER-2 overexpression, Basal-like and Normal breast-like subtype, based on the differently expressed genes in breast cancer tissue. The Hippo signaling pathway plays an indispensable role in BC. The YAP gene is a terminal effector of Hippo pathway, and hyperactivation of YAP mediates tumorigenesis. As an inhibitor of YAP, non-photoactivated verteporfin (VP) can inhibit YAP-mediated tumor proliferation and angiogenesis by eliminating its interaction with TEAD. This study aimed to determine the effect and molecular mechanisms of VP-mediated inhibition of YAP in different subtypes of BC.

Methods: Luminal A, Luminal B and Basal-like BC cells were cultivated in vitro to study effects of VP on proliferation and apoptosis of these three molecular BC subtypes.

Results: Our experimental results showed that VP inhibited cell proliferation, YAP-TEAD interaction and expression of its downstream targets. VP also induced tumor cell apoptosis, and promoted the cleavage of Caspase-9 and PARP in the cells of various molecular subtypes of BC.

Conclusion: These findings provide a basis for the use of VP as a potential anti-tumor therapeutic for BC by targeting the Hippo pathway effector YAP.
\end{abstract}

Keywords: Breast cancer, YAP, Verteporfin, Cell proliferation, Apoptosis

\section{Background}

Breast cancer $(\mathrm{BC})$ is a common malignant tumor with over 250,000 newly diagnosed cases reported every year [1]. The treatment regimen for $\mathrm{BC}$ depends primarily on the level of the estrogen receptor (ER), progesterone receptor (PR), human epidermal growth factor receptor-2 (HER-2) and Ki-67 in tumor patients. In addition to

\footnotetext{
* Correspondence: drlixqi@hotmail.com

'Shandong University of Traditional Chinese Medicine, Jinan, Shandong Province, China

2Department of Breast Surgery, The Second Affiliated Hospital of Shandong First Medical University, No.706 TaiShan Road, TaiShan District, Tai'an 271000, Shandong Province, China
}

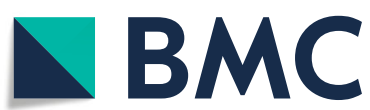

(c) The Author(s). 2020 Open Access This article is licensed under a Creative Commons Attribution 4.0 International License, which permits use, sharing, adaptation, distribution and reproduction in any medium or format, as long as you give appropriate credit to the original author(s) and the source, provide a link to the Creative Commons licence, and indicate if changes were made. The images or other third party material in this article are included in the article's Creative Commons licence, unless indicated otherwise in a credit line to the material. If material is not included in the article's Creative Commons licence and your intended use is not permitted by statutory regulation or exceeds the permitted use, you will need to obtain permission directly from the copyright holder. To view a copy of this licence, visit http://creativecommons.org/licenses/by/4.0/ The Creative Commons Public Domain Dedication waiver (http://creativecommons.org/publicdomain/zero/1.0/) applies to the data made available in this article, unless otherwise stated in a credit line to the data.

traditional surgery, the different subtypes of BC may require endocrine therapy, chemotherapy, radiotherapy, and biologically-targeted treatment [2, 3]. However, early metastasis and drug resistance have been associated with a poor prognosis for BC [4]. Hence, the identification of reliable molecular targets and targeted drugs for breast cancer patients to improve prognosis and treatment efficacy are urgently required.

The Hippo signaling pathway, which performs the main function of inhibiting cell proliferation and limiting organ overgrowth, is found in Drosophila melanogaster and is highly conserved in mammals [5]. YAP is the final 
effector of the Hippo pathway. When dephosphorylated, YAP is localized to the nucleus and binds to TEAD and acts as a transcriptional co-activator. YAP-TEAD mediates the expression of different oncogenes including those that regulate the tumor cell cycle, epithelial mesenchymal transition, migration, invasion, and chemoresistance [6]. Gene mutations and changes in the expressions of essential Hippo pathway components encourage the occurrence and development of breast cancer. Overexpression of YAP can significantly stimulate the proliferation of tumor cells [7]. Additionally, the expression of YAP has been found to be correlated with specific molecular subtypes of $\mathrm{BC}$ [8].

Clinically, Verteporfin (VP) has been utilized as a porphyrinic photosensitizer for the photodynamic treatment of neovascular macular degeneration for a long time [9]. Based on the previous research, non-photoactivated VP selectively binds to YAP and changes the YAP conformation process, thereby eliminating its interaction with TEAD [10]. In addition, VP blocks YAP function by increasing the level of $14-3-3 \sigma$ protein in the cytoplasm [11]. Numerous studies have also shown that VP downregulated the transcription of YAP, which then inhibits cell proliferation-related genes, including cylinD1, cyclinE1, and TEAD in multiple tumor cells [12].

In this study, we assessed the influence and mechanism by which VP exerts its effects on the proliferation and apoptosis of Luminal A, Luminal B and Basal-like molecular subtypes of $\mathrm{BC}$ in relation to YAP. Our findings provide a novel theoretical basis for the use of $\mathrm{VP}$ in the treatment of $\mathrm{BC}$.

\section{Methods}

\section{Cell culture}

Human Luminal A breast cancer cell line MCF-7, Luminal B breast cancer cell line BT-474 and Basal-like subtype cell line BT-549 [13] were bought from Zhongqiao Xinzhou Biology (Shanghai, China). MCF-7, BT474 and BT-549 were maintained in RPMI-1640 (Hyclone, Logan, Utah, USA) supplemented with 10\% FBS (Gibco, Carlsbad, CA, USA) and placed in a at 5\% $\mathrm{CO} 2$ incubator at $37^{\circ} \mathrm{C}$. Verteporfin was bought from MCE (St Louis, USA).

\section{Cell viability assay}

The MCF-7, BT-474 and BT-549 cells were added into 96-well plates at density of $4 \times 104$ cells per well. After incubation with VP, cell viability was assessed though CCK- 8 assay (DOJINDO) at 24, 48 , and $72 \mathrm{~h}$. In brief, $10 \mu \mathrm{l}$ of the CCK8 mixture was added into each well and the cells plates were placed in $37^{\circ} \mathrm{C}$ incubator for $1.5 \mathrm{~h}$. Absorbance was determined at a wavelength of $450 \mathrm{~nm}$.

\section{Real-time PCR (RT-PCR)}

Total RNA was extracted from VP-incubated cells utilizing the TRIzol regent (Invitrogen; Thermo Fisher Scientific, Inc.) using established protocol. cDNA was synthesized using the PrimeScript reverse transcription reagent kit (TIANGEN BIOTECH Co., Beijing, China) by following established guidelines. cDNA was assessed using qPCR on a SuperReal PreMix Plus (SYBR Green) system (TIANGEN BIOTECH Co.). The amplification conditions included: $95^{\circ} \mathrm{C}$ for 15 min, 40 cycles of $95^{\circ} \mathrm{C}$ for $20 \mathrm{~s}, 56^{\circ} \mathrm{C}$ for $30 \mathrm{~s}$ and $68^{\circ} \mathrm{C}$ for $30 \mathrm{~s}$. The primer sequences used for qPCR were: YAP forward (F) $5^{\prime}$-TGACCCTCGTTTTGCCATGA-3' and reverse (R), 5'-GTTGCTG CTGGTTGGAGTTG-3'; CTGF F, 5'TGGAAGAGAACATTAAGAA GGGCA-3' and R, 5'TGCAGCCAGAAAGCTCAAAC-3'; AXL F, 5'-ACCC CAG AGGTGCTAATGGA-3' and R, 5'-GTGGACTGGC TG TGCTTCC-3'; CYR61 F, 5'-GCAAGGAGCTGGGA TTCGAT-3' and R,5'-ATTCCAAAAACAGGGAGCCG3'; GAPDH F, 5'-GCACCGTCAAGGCTGAGAAC-3' and R, 5'-TGGTGAAGACGC CAGTGGA-3'. GAPDH functioned as the internal control. Gene expression was measured utilizing the $2-\Delta \Delta \mathrm{Ct}$ method.

\section{Apoptosis assay}

In order to determine the levels of cell apoptosis, the VP-incubated cells were washed and fixed at $4{ }^{\circ} \mathrm{C}$ with $4 \%$ paraformaldehyde for $30 \mathrm{~min}$. After another wash, cells were incubated with $0.2 \%$ TritonX-100 for $15 \mathrm{~min}$ at room temperature, and cytometrically assessed using Principle In Situ Cell Death Detection Kit (Roche, Inc.), following established guidelines.

\section{Protein extraction and western blotting analysis}

Total proteins were extracted utilizing RIPA lysis buffer that contained phosphatase and protease inhibitors. Protein concentration was evaluated utilizing a bicinchoniniacid assay (Solarbio, Beijing). The later steps of the western blotting analysis were conducted using standard protocol. Antibody directed towards GAPDH was acquired from Novus Biologicals, while antibodies directed towards YAP, TEAD, Bcl-2, BAX, p-YAP (Ser127), CYR61, CTGF, AXL, Caspase9, Cleaved Caspase9, PARP, and Cleaved PARP were bought through Cell Signaling Technology (Danvers, MA).

\section{Statistical analyses}

Data were represented as mean \pm standard deviation. Comparisons were conducted utilizing an unpaired 2tailed Student t-test. The GraphPad Prism 5 software was utilized to assess statistical significance. $P<0.05$ indicated statistical significance. 


\section{Results}

YAP levels in different subtypes of BC cells

Western blotting analysis results showed that YAP was expressed in MCF-7, BT-474 and BT-549 cells. The expression of YAP in Luminal B BT-474 BC cells and triple negative breast cancer (TNBC) BT-549 cells were significantly higher than that in Luminal A MCF-7 cell. BT474 cells showed the highest level of YAP expression among the three different subtypes of BC cell lines $(P<$ 0.001) (Fig. 1).

The effect of verteporfin on the proliferation of different molecular subtypes of BC cells

Data from the CCK-8 test demonstrated that VP could suppress MCF-7, BT-474 and BT-549 cell growth in a dose-dependent manner, in comparison with the untreated MCF-7, BT-474 and BT-549 cells (Fig. 2a). Comparison between different molecular subtypes of BC cells under the same drug concentration found that after $24 \mathrm{~h}$ of VP treatment, the proliferation of BT-549 cells decreased most significantly. After treatment with 8 and $16 \mu \mathrm{m}$ VP for $48 \mathrm{~h}$, there was a statistically significant difference in the proliferation rate of different $\mathrm{BC}$ subtypes as compared with untreated cells $(P<0.05)$ (Fig. 2a). Altogether, VP decreased proliferation in all cell lines within 48-72 h compared with untreated cells.

\section{Verteporfin regulates the expression of YAP, TEAD and YAP-TEAD downstream targets}

As shown through the results of the Western blotting analysis, VP blocked YAP, p-YAP and TEAD protein expression in MCF-7, BT-474 and BT-549 cells (Fig. 3a). As the concentration of VP increased, the expressions of AXL and CYR61 proteins in different subtypes of breast cancer cells were downregulated. In addition, VP inhibited the expression of CTGF in BT-474 and BT-549 cells (Fig. 3b). VP also inhibited YAP-TEAD transcription in MCF-7, BT-474 and BT-549 cells in vitro. The RT-PCR results show that, in comparison with the controls, YAP, AXL and CYR61 mRNA expression levels in MCF-7,
BT-474 and BT-549 cells decreased significantly after treatment with 4,8 and $12 \mu \mathrm{M}$ VP. Treatment with VP also downregulated the mRNA expression of CTGF in BT-474 and BT-549 cells (Fig. 3c). In brief, VP decreased the expression of YAP-TEAD downstream targets by inhibiting the expression of YAP and TEAD.

\section{Verteporfin induces cell apoptosis by disrupting YAP- TEAD interaction}

TUNEL experiments showed that VP induced apoptosis in MCF-7, BT-474 and BT-549 cells (Fig. 4a). The western blot data indicated that treatment with $\mathrm{VP}$ led to the apoptosis of different subtypes of BC cells through decreased expression of the YAP downstream target gene Survivin (Fig. 4b), Bcl-2 and the ratio of Bcl-2/BAX, compared with the controls. Additionally, VP treatment led to an increase in levels of BAX (Fig. 4c), cleaved Caspase-9 and cleaved PARP proteins (Fig. 4d). These results demonstrated that VP, an inhibitor of the Hippo YAP signaling pathway, was highly conducive for inducing apoptosis among different molecular subtypes of BC cells by upregulating levels of cleaved Caspase-9, cleaved PARP, and downregulating the ratio of $\mathrm{BAX} / \mathrm{Bcl}-2$.

\section{Discussion}

$\mathrm{BC}$ is the leading malignant type of tumor among females worldwide. In order to identify treatment targets for $\mathrm{BC}$, it is important to analyze the genetic differences between normal and tumor cells. $\mathrm{BC}$ can be separated into five subclassifications: Luminal A, Luminal B, HER2 overexpression, Basal like type and Normal breast-like subtype. The expression of PR and HER-2 can be used as the further indicators for the differentiation between Luminal A and Luminal B $[14,15]$. Although the efficacy of clinical treatment methods for $\mathrm{BC}$ have progressed greatly, there are still only a limited number of treatment options for patients who experience chemotherapy resistance and metastasis [16]. Moreover, TNBC, which has been described using the deficiency of ER, PR, and HER-2, has been found to be associated with the worst

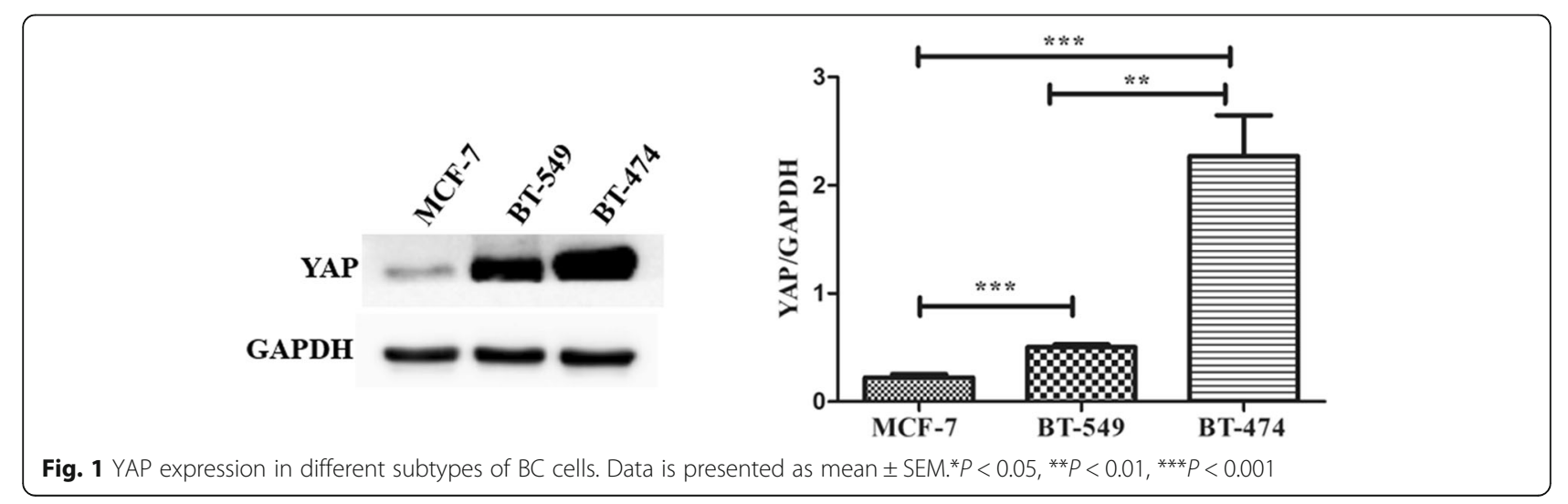



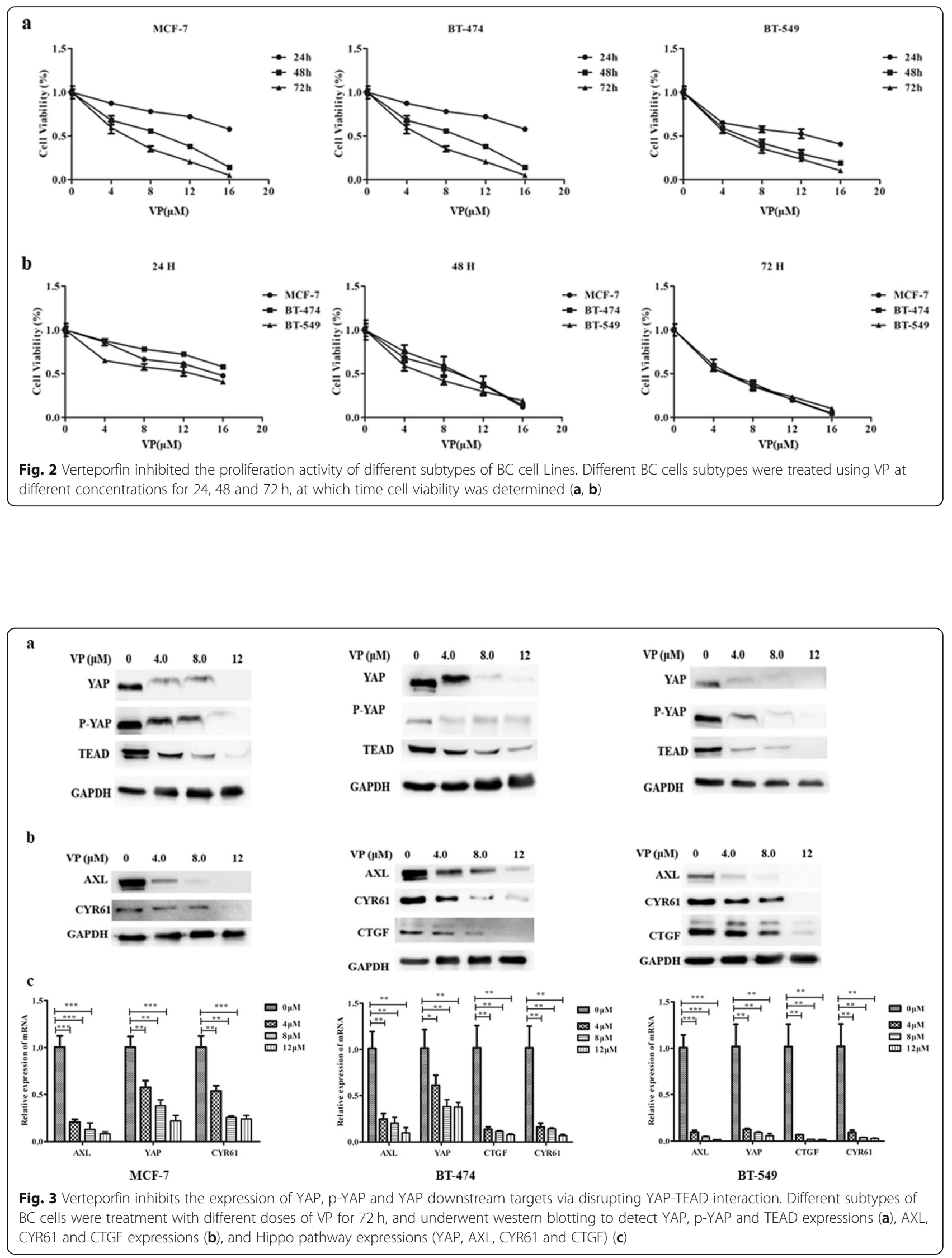


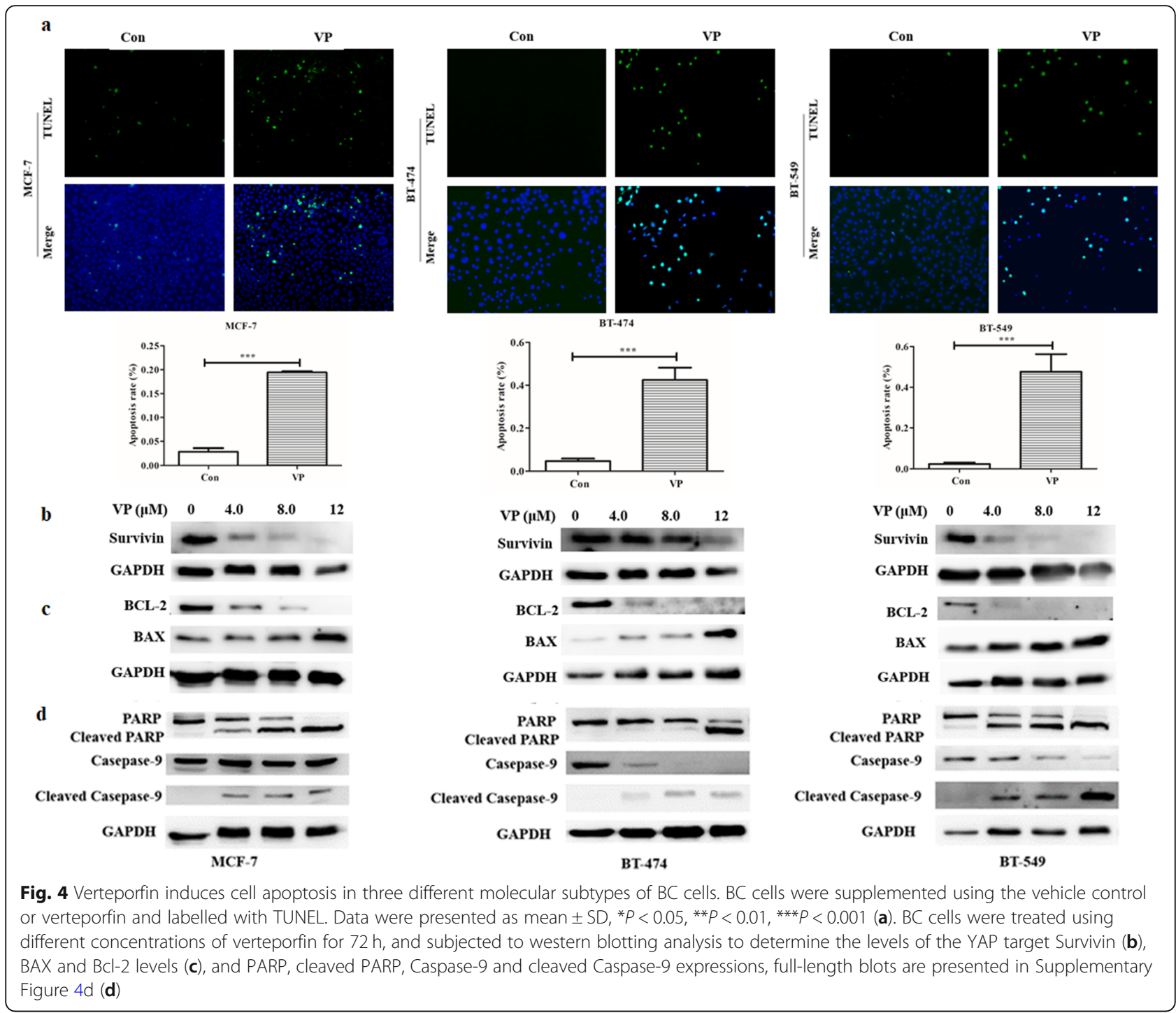

prognosis due to increased rates of recurrence and a lack of effective targeted therapies among all major subtypes of $\mathrm{BC}$ [17].

Hippo is a complex tumor regulation pathway, and its deregulation has been found to be associated with changing normal state into a pathological cancer state. As the main effector of Hippo, YAP is phosphorylated by the Hippo Core complex and degraded in the cytoplasm [6]. When the Hippo upstream pathway is suppressed, hyperactivation of TEAD as a transcription factor requires the involvement of YAP as a coactivator to mediate downstream target gene transcriptional activity. Thus, YAP is translocated into the nucleus and promotes proliferation, metastatic development, and stem cell maintenance of cancer cells [18]. Knockdown of AXL, one of the YAP-TEAD target genes, decreases the growth and invasiveness of tumor xenographs [19]. Similarly, dysregulation of CTGF and CYR61 are strongly correlated with development of $\mathrm{BC}$, prostate cancer and malignant melanoma [20-22]. Survivin plays a key role in controlling cell apoptosis, cell cycle and drug resistance [23, 24]. All of these functions depend on the interaction between YAP and TEAD transcription factors. Therefore, it can be observed that YAP exerts its oncogenic function by combining with the transcription factor TEAD to encourage the expression of genes that play a role in the progression and metastasis of cancer.

Several studies have demonstrated that VP decreased transcriptional activity of YAP by competitively binding to YAP and abrogating the interaction between YAP with TEAD, which blocks YAP-TEAD-stimulated tumorigenesis [12]. Mutations and the subsequent altered expression of YAP promoted the proliferation, invasion, and chemotherapy resistance of breast cancer cells. YAP plays a pivotal role in the proliferation, invasion, and chemotherapy resistance of breast cancer cells. 
YAP deficiency decreased lung metastasis ability in a breast cancer mouse model [25, 26]. Disruption of the interaction between YAP and TEAD not only weakened the expression of YAP downstream target genes, but also inhibited the proliferation, EMT and oncogenic transformation ability of many tumor cells. The YAP-TEAD complex is the last step in the transcriptional activity of YAP in the Hippo pathway, which caused the targeted blockade of YAP-TEAD by VP on the upstream proteins of the Hippo pathway and minimal side effects were expected. Our data demonstrated that VP inhibited the growth of the different subtypes of $\mathrm{BC}$ cells, and VP treatment efficiently prevented YAP-TEAD transcriptional activity. CCK8 analysis revealed that the TNBC BT-549 cell line was the most sensitive to the inhibitory effect caused by VP on cell proliferation. VP treatment led to YAP, AXL, CYR61 and/or CTGF downregulation in the $\mathrm{BC}$ cell lines of different subtypes, suggesting that these effectors may act as their own target genes as described in TNBC MDA-MB-231 cells, VP could inhibit the transcriptional activity of TEAD, reduce the protein expression levels of YAP target genes, AXL and CTGF, inhibit the migration, and induce the apoptosis of paclitaxel resistant MDA-MB-231 cells [27-29]. The results of western blotting analysis proved that the protein and mRNA expressions of YAP, as well as of YAP targeted genes decreased along with the increase in the concentration of VP. Compared with the untreated group, the expression levels of YAP, TEAD and Survivin in BT-474 cells decreased after $4 \mu \mathrm{M}$ VP treatment $(P<0.05)$. However, when compared with the untreated group, the expression levels of YAP, TEAD and Survivin in MCF-7 and BT-549 cells at $4 \mu \mathrm{M}$ VP treatment had decreased significantly reduced $(P<0.01)$. Similarly, at $4 \mu \mathrm{M}$ VP treatment, the expression of YAP mRNA in BT-474 cells were downregulated, compared with that of the untreated group $(P<$ $0.05)$, while the expression of YAP mRNA levels in MCF7 and BT-549 cells showed a statistically significant difference, compared with the untreated group $(P<0.01)$.

Recently, studies have shown that non-photoactivated VP could induce the apoptosis of melanoma and pancreatic cancer cells through the activation of apoptosis-related proteins caused by preventing YAP-TEAD interaction [30-32]. Our results have demonstrated that VP induced the apoptosis of MCF-7, BT-474, and BT-549 cells by upregulating levels of BAX, cleaved Caspase-9, and cleaved PARP, and downregulating the level of Bcl-2. Furthermore, our western blotting analysis results indicated that the expression levels of cleaved PARP in MCF-7 and BT-549 cells were statistically different $(P<0.05)$ compared with the untreated group. Nevertheless, in BT-474 cells, no significant difference was found in cleaved PARP levels, compared with the untreated group $(P>0.05)$. Moreover, compared with the untreated group, there was a significant difference of in the expression of cleaved PARP in MCF-7 and BT-474 cells $(P<0.01)$ at $8 \mu \mathrm{M}$ VP treatment, and a similar result was found in BT-474 cells $(P<0.05)$.

The studies of VP in breast cancer mainly focus on TNBC MDA-MB-231 cells, VP $(1 \mu \mathrm{mol} / \mathrm{L})$ inhibits the growth of the paclitaxel-resistant breast cancer cell line MDA-MB-231 [28], VP $(10 \mu \mathrm{M}, 3 \mathrm{~h})$ reduced the expression of YAP in the ZNF367-overexpressing breast cancer MDA-MB-231 and 4T1 cells, and significantly reduced lung metastases in mouse models [33], and sensitizes the HER-2 positive breast cancer cell line HCC1569 to lapatinib [34]. The purpose of this study was to explore the effect of VP on different subtypes of BC and its mechanism by targeting YAP gene under the condition of nonphotoactivation. On the basis of existing data, we further supplemented the effect of VP on TNBC BT-549 cells, Luminal A MCF-7 cells and Luminal B (ER+, PR+, HER-2+) BT-474 cells in vitro. Meanwhile, we found that YAP was highly expressed in BT474 cells, which may increase the hope of targeted therapy for Luminal B and HER2+ patients besides endocrine and anti-HER2 therapy. These encouraging results suggested that the use of VP may be a promising strategy for the treatment of BC.

Experimental verification of various tumors indicated that targeting the Hippo pathway is an effective method of treating cancers [6]. Proteins of the CCN (CTGF/CYR61/ NOV) family exhibit different levels of expression and transcription in different tumor tissues. Changes in the transcriptional activity of $\mathrm{CCN}$ have been found to be extremely important during tumorigenesis. $\mathrm{CCN}$ intervenes in embryonic development, angiogenesis, tumor heterogeneity and progression through various signaling pathways, including the Hippo pathway $[35,36]$. Genetic studies have indicated that a stable level of CYR61 in MCF-7 cells could significantly counteract paclitaxelinduced apoptosis and increase chemotherapy resistance to doxorubicin [37]. In our study, we found that the treatment with VP downregulated the expression of CYR61 in Luminal A MCF-7 cells suppressing the proliferation of MCF-7 cells and providing a new treatment strategy for Luminal A endocrine patients. Our study found differential expression of CTGF in the three subtypes of BC. Interestingly, high level of expression of CTGF was observed in BT-549 cells, while CTGF expression was not detected in MCF-7 cells, which was concordant with the results of previous studies [38]. The activation of CTGF and CYR61 may exert divergent roles on the biological processes of different subtypes of $\mathrm{BC}$.

Although based on theoretical concepts, there are still several problems with the use of VP as an inhibitor of $\mathrm{YAP} / \mathrm{TEAD}$ interaction, $\mathrm{VP}$ is a photosensitizer drug that is already in clinical use. Cell exposure must be strictly controlled to avoid exposure to light. At present, no studies have declared the effects of YAP caused by 
photoactivated VP. Furthermore, the exact mechanism by which VP is able to affect the Hippo signaling pathway still needs to be evaluated in greater depth. More importantly, our study may pave the way for further drug development for $\mathrm{BC}$.

\section{Conclusions}

In conclusion, our data demonstrated that VP treatment inhibited the proliferation of MCF-7, BT-474 and BT549 cells, with the main difference observed during short treatment periods $(24 \mathrm{~h})$ was that TNBC BT-549 cell lines responded faster than the others. VP also induced cell apoptosis by disrupting YAP-TEAD interaction, which led to a decrease in Survivin levels and the Bcl-2/ BAX ratio, and cleavage of PARP and Caspase-9 in Luminal A MCF-7, Luminal B BT-474 and TNBC BT-549 cells in vitro. Repositioned VP targeting of YAP-TEAD activity may provide a theoretical basis for the development of VP as a novel targeted therapy, adjuvant therapy and precision treatment for breast cancer.

\section{Supplementary Information}

The online version contains supplementary material available at https://doi. org/10.1186/s12885-020-07555-0.

\section{Additional file 1. \\ Additional file 2 . \\ Additional file 3.}

\section{Abbreviations}

ER: Estrogen receptor; PR: Progesterone receptor; HER-2: Human epidermal growth factor receptor-2; BC: Breast cancer; TNBC: Triple negative breast cancer

\section{Acknowledgements}

Not applicable.

\section{Authors' contributions}

X.Q.L., C.R.W., designed experiments, wrote the main manuscript text, X.Q.L., C.R.W., performed experiments and prepared the figures. All authors have read and approved the manuscript.

\section{Funding}

This work was supported by the following projects: the National Natural Science Foundation of China (No81473687), Shandong Provincial Natural Science Foundation, China (No ZR2009CM039 and No ZR2013HM038). High level project cultivation program of Shandong First Medical University, China (No 2018GCC14), Academic promotion of Shandong First Medical University, China (grant no. 2019QL017).

\section{Availability of data and materials}

The datasets used and/or analysed during the current study are available from the.

corresponding author on reasonable request.

\section{Ethics approval and consent to participate}

Not applicable.

\section{Consent for publication}

Not applicable.

\section{Competing interests}

The authors report no conflicts of interest in this work.

Received: 7 February 2020 Accepted: 22 October 2020

Published online: 29 October 2020

\section{References}

1. Bray F, Ferlay J, Soerjomataram I, et al. Global cancer statistics 2018: Globocan estimates of incidence and mortality worldwide for 36 cancers in 185 countries. CA Cancer J Clin. 2018;68(6):394-424.

2. Duffy MJ, Harbeck N, Nap M, et al. Clinical use of biomarkers in breast cancer: updated guidelines from the European group on tumor markers (EGTM). Eur J Cancer. 2017:4(75):284-98.

3. Núñez C, Capelo JL, Igrejas G, et al. An overview of the effective combination therapies for the treatment of breast cancer. Biomaterials. 2016;97:34-50

4. Ginsburg O, Bray F, Coleman MP, et al. The global burden of women's cancers: a grand challenge in global health. Lancet. 2016;389(10071):847-60.

5. Justice RW, Zilian O, Woods DF, et al. The drosophila tumor suppressor gene warts encodes a homolog of human myotonic dystrophy kinase and is required for the control of cell shape and proliferation. Genes Dev. 1995; 9(5):534-46.

6. Fu V, Plouffe SW, Guan KL. The hippo pathway in organ development, homeostasis, and regeneration. Curr Opin Cell Biol. 2017:49:99-107.

7. Yao CB, Zhou X, Chen CS. The regulatory mechanisms and functional roles of the hippo signaling pathway in breast cancer. Yi Chuan. 2017:39:617-29.

8. Vlug EJ, Van De Ven RAH, et al. Nuclear localization of the transcriptional coactivator YAP is associated with invasive lobular breast cancer. Cell Oncol. 2013;36(5):375-84

9. Battaglia Parodi M, La Spina C, Berchicci L, et al. Photosensitizers and photodynamic therapy: Verteporfin. Dev Ophthalmol. 2016;55:330-6.

10. Liu-Chittenden, Y, Huang, B, Shim, J. S, et al. Genetic and pharmacological disruption of the TEAD-YAP complex suppresses the oncogenic activity of YAP. Genes Dev, 2012, 26(12):1300-1305.

11. Wang $C$, Zhu $X$, Feng $W$, et al. Verteporfin inhibits YAP function through upregulating 14-3-3 $\sigma$ sequestering YAP in the cytoplasm. Am J Cancer Res. 2015;6(1):27-37.

12. Gibault F, Corvaisier M, Bailly F, et al. Non-photoinduced biological properties of Verteporfin. Curr Med Chem. 2016:23(11):1171-84.

13. Neve RM, Chin K, Fridlyand J, et al. A collection of breast cancer cell lines for the study of functionally distinct cancer subtypes. Cancer Cell. 2006; 10(6):515-27.

14. Prat A, Cheang MC, Martín M, et al. Prognostic significance of progesterone receptor positive tumor cells within Immunohistochemically defined luminal a breast cancer. J Clin Oncol. 2013;31(2):203-9.

15. Network TCGA. Comprehensive molecular portraits of human breast tumours. Nature. 2012;490(7418):61-70.

16. Hart CD, Migliaccio I, Malorni L, et al. Challenges in the management of advanced, ER-positive, HER2-negative breast cancer. Nat Rev Clin Oncol. 2015:12:541-52.

17. Dey N, De P. PI3K-AKT-mTOR inhibitors in breast cancers: from tumor cell signaling to clinical trials. Pharmacol Ther. 2017;175:91-106.

18. Yuhang $Z$, Tingting $H$, Alfred $C$, et al. The TEAD family and its oncogenic role in promoting tumorigenesis. Int J Mol Sci. 2016;17(1):138-53.

19. Gjerdrum C, Tiron C, Hoiby T, et al. Axl is an essential epithelial- tomesenchymal transition-induced regulator of breast cancer metastasis and patient survival. Proc Natl Acad Sci. 2010;107(3):1124-9.

20. Xie D, Nakachi $K$, Wang $H$, et al. Elevated levels of connective tissue growth factor, WISP-1, and CYR61 in primary breast cancers associated with more advanced features. Cancer Res. 2001;61(12):8917-23.

21. Yang F. Stromal expression of connective tissue growth factor promotes angiogenesis and prostate cancer tumorigenesis. Cancer Res. 2005;65(19): 8887-95.

22. Hutchenreuther J, Vincent KM, Carter DE, et al. CCN2 expression by tumor Stroma is required for melanoma metastasis. J Investigative Dermatology. 2015;135(11):2805-13.

23. Salvesen GS, Duckett CS. Apoptosis: IAP proteins: blocking the road to death's door. Nat Rev Mol Cell Biol. 2002;3(6):401-10.

24. Peery RC, Liu JY, Zhang JT. Targeting survivin for therapeutic discovery: past, present, and future promises. Drug Discov Today. 2017;22(10):1466-77. 
25. Chen Q, Zhang N, Gray RS, et al. A temporal requirement for hippo signalling in mammary gland differentiation, growth and tumorigenesis. Genes Dev. 2014;28(5):432-7.

26. Rashidian J, Le Scolan E, Ji X, et al. Ski regulates Hippo and TAZ signalling to suppress breast cancer progression. Sci Signal. 2015;8(363):ra14.

27. Qin X, Li J, Sun J, et al. Low shear stress induces ERK nuclear localization and YAP activation to control the proliferation of breast cancer cells. Biochem Biophys Res Commun. 2019;510(2):219-23.

28. Li Y, Wang $S$, Wei $X$, et al. Role of inhibitor of yes-associated protein 1 in triple-negative breast cancer with taxol-based chemoresistance. Cancer Sci. 2019:110(2):561-7.

29. Gibault F, Bailly F, Corvaisier M, et al. Molecular features of the YAP inhibitor Verteporfin: synthesis of Hexasubstituted Dipyrrins as potential inhibitors of YAP/TAZ, the downstream effectors of the hippo pathway. ChemMedChem. 2017:12(12):954-61.

30. Ma YW, Liu YZ, Pan JX. Verteporfin induces apoptosis and eliminates cancer stem-like cells in uveal melanoma in the absence of light activation. Am J Cancer Res. 2016;6(12):2816-30.

31. Yu F-X, et al. Mutant Gq/11 Promote Uveal Melanoma Tumorigenesis by Activating YAP. Cancer Cell. 2014;25(6):822-30.

32. Wei $H$, Wang $F$, Wang $Y$, et al. Verteporfin suppresses cell survival, angiogenesis and vasculogenic mimicry of pancreatic ductal adenocarcinoma via disrupting the YAP-TEAD complex. Cancer Sci. 2017; 108(3):478-87.

33. Wu X, Zhang X, Yu L, Zhang C, Ye L, Ren D, et al. Zinc finger protein 367 promotes metastasis by inhibiting the hippo pathway in breast cancer. Oncogene. 2020;39(12):2568-82.

34. Lin CH, Pelissier FA, Zhang H, Lakins J, Weaver VM, Park C, et al. Microenvironment rigidity modulates responses to the HER2 receptor tyrosine kinase inhibitor lapatinib via YAP and TAZ transcription factors. Mol Biol Cell. 2015;26(22):3946-53.

35. Jun LI, Lin YE, Owen $\mathrm{S}$, et al. Emerging role of CCN family proteins in tumorigenesis and cancer metastasis. Int J Mol Med. 2015;36(6):1451-63.

36. Chien W, O'Kelly J, Lu D, et al. Expression of connective tissue growth factor (CTGF/CCN2) in breast cancer cells is associated with increased migration and angiogenesis. Int J Oncol. 2013;38(6):1741-7.

37. Zhang C, Luo X, Liu L, et al. Myocardin-related transcription factor a is upregulated by $17 \beta$-estradiol and promotes migration of MCF-7 breast cancer cells via transactivation of MYL9 and CYR61[J]. Acta Biochim Biophys Sin. 2013;45(11):921927.

38. Li MH, Sanchez T, Pappalardo A, et al. Induction of anti-proliferative connective tissue growth factor expression in Wilms' tumor cells by sphingosine-1-phosphate receptor 2[]]. Mol Cancer Res. 2008;6:1649-56.

\section{Publisher's Note}

Springer Nature remains neutral with regard to jurisdictional claims in published maps and institutional affiliations.

Ready to submit your research? Choose BMC and benefit from:

- fast, convenient online submission

- thorough peer review by experienced researchers in your field

- rapid publication on acceptance

- support for research data, including large and complex data types

- gold Open Access which fosters wider collaboration and increased citations

- maximum visibility for your research: over $100 \mathrm{M}$ website views per year

At $\mathrm{BMC}$, research is always in progress.

Learn more biomedcentral.com/submissions 